\title{
Distribution of seasonality of calving patterns and milk production in dairy herds across the United States
}

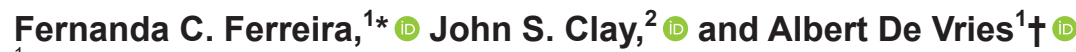 \\ ${ }^{1}$ Department of Animal Sciences, University of Florida, Gainesville 32611 \\ ${ }^{2}$ Dairy Records Management Systems, Raleigh, NC 27603
}

\begin{abstract}
Calving patterns and milk production are seasonal throughout the United States; however, the distribution of seasonality, and the extent to which this seasonality is due to direct effects of climate on milk production and reproductive performance or farm management, is not well quantified. Summer-to-winter (SW) ratios have been used as measures of seasonality, but other measures such as low-to-peak (LP) ratios have been proposed. Our objectives were (1) to describe the distribution of seasonality in calving pattern and milk production among herds in the United States, (2) to compare SW and LP ratios of calving pattern and milk production, (3) to quantify the effect of a seasonal calving pattern, parity, and percentage of dry cows on seasonality of milk production, and (4) to describe the association between seasonality in calving pattern and milk production, herd size, and daily milk production per cow. The final data set contained Dairy Herd Improvement Association lactation records from 2015 from 5,292 (calving pattern) and 5,200 (milk production) herds for 41 states in the United States. We used generalized linear regression models with 1 sinusoidal curve to model calving pattern and milk production per cow for each herd. For milk production, a model adjusting for days in milk (DIM) and the interaction of DIM and parity (ADJ) and a model that was not adjusted (NO) were run. Both models included the effect of the percentage of dry cows. We used SW and LP ratios calculated from the parameters of the sinusoidal component of the models as measures of seasonality. The variability within states for all seasonality measures was large. The median LP ratio of calving pattern was 0.61 , and small herds were more seasonal (LP ratio 0.56) than large herds (LP ratio 0.75). For milk production, the

Received December 30, 2019.

Accepted April 27, 2020.

*Current address: University of California, Davis, Veterinary Teaching and Research Center, 18830 Road 112, Tulare, CA 93274.

†Corresponding author: devries@ufl.edu
\end{abstract}

median LP ratio- $\mathrm{NO}$ was 0.88 , and the $\mathrm{LP}$ ratio-ADJ was 0.90. Small herds were more seasonal (0.89) than large herds (0.92) when their LP ratios-ADJ were compared. States in the south of the United States were the most seasonal for calving patterns and milk production. Adjusting for DIM and parity increased the LP ratio of milk production by $8.9 \%$ for $66 \%$ of the herds. Adjusting for the percentage of dry cows increased the LP ratio in $72.9 \%$ of the herds by a median value of $21.8 \%$. The correlations between SW and LP ratios were weak. Herds that were more seasonal for milk production had a lower average daily milk per cow than less-seasonal herds. In conclusion, seasonality in calving patterns and milk production among herds varied greatly across the United States. Sinusoidal models with covariates allowed for quantification of the effects of calving pattern, DIM, and parity on the seasonality in milk production. The LP ratios captured the maximum seasonality better than SW ratios did.

Key words: seasonality, calving, milk, sinusoidal

\section{INTRODUCTION}

Seasonality is a cyclical variation observed in data over a period of time, corresponding to seasons or other calendar periods (Sargeant et al., 1998; Fisman, 2007). Milk production follows a yearly seasonal pattern throughout the United States, as shown by the Federal Milk Marketing Order Areas (USDA-AMS, 2019). In 2018, the maximum variation in average daily delivery of milk per producer to regulated handlers in each month (compared with the annual average) was $6 \%$ in the Pacific Northwest Federal Milk Marketing Order Area and $12 \%$ in the Southwest Federal Milk Marketing Order Area. Seasonal changes in milk production across the United States and the world are extensively reported in the literature (for example, Allore et al., 1997; Washington et al., 2002; Ferreira and De Vries, 2015; Bernabucci et al., 2015; Salfer et al., 2019). The distribution of seasonality among herds within states in the United States is not well documented, however. We reported on the seasonality of milk production and bulk 
tank SCC in dairy herds in Florida (Ferreira and De Vries, 2015). Salfer et al. (2019) reported seasonality in milk production in herds in Pennsylvania. Quantification of seasonality of cow performance may show the lack of success of heat abatement (Flamenbaum and Ezra, 2007) or may guide management decisions such as breeding and replacement (De Vries, 2004).

One of the major causes of seasonality in milk production is heat stress (West, 2003; Baumgard and Rhoads, 2012; Schüller et al., 2016), and its negative effects are well documented (Baumgard and Rhoads, 2012; Schüller et al., 2017; Tao et al., 2018). More recently, the effects of an endogenous circannual rhythm on milk production and components have been demonstrated as well (Salfer et al., 2019). In addition, management decisions may exacerbate this seasonal pattern. For example, some farmers deliberately delay breeding or rebreeding to overcome the lower reproductive performance or to avoid calving during the hotter periods of the year, or both (Washburn et al., 2002; Oseni et al., 2003; DeJarnette et al., 2007). The negative effects of heat stress on reproduction and the delay in breeding result in an increased seasonal calving pattern in the herd. As a result, a variation in the average DIM along the year partially explains seasonal differences in milk production (Olde Riekerink et al., 2007; Chen et al., 2014; Shock et al., 2015).

Various measures of seasonality of reproduction or milk production have been used as proxies for the severity of heat stress, especially the summer-to-winter ratio (SW; Flamenbaum and Ezra, 2007; Flamenbaum and Galon, 2010; Guinn et al., 2019). This is a traditional measure of seasonality, in which the average value of milk production per cow, for instance, during the summer is divided by the average value during the winter. Although straightforward, the SW ratio does not allow for adjustment of covariates that may explain some of the seasonality, such as cows' DIM. To overcome the effect of variation in DIM on the SW ratio, one could use a variable that is already adjusted for DIM, such as a standardized milk production (Flamenbaum and Ezra, 2007). However, standardized performance measures are not always available, and currently used methods of standardization have not been updated in decades. In addition, the SW ratio is not able to capture the maximum seasonality if the timing of the peak and nadir of the variable do not occur during summer and winter.

A more desirable measure of seasonality would allow simultaneously for adjustment for covariates and for identification of the exact timings of the peak and the nadir in the year. This can be achieved by the use of sinusoidal curves in generalized linear models, with low-to-peak (LP) ratios as a measure of seasonality
(Stolwijk et al., 1999; Christensen et al., 2011; Salfer et al., 2019).

Despite the number of reports describing and explaining causes of seasonality in the literature, only a few studies have attempted to report how average seasonality in milk production is distributed across the United States (Guinn et al., 2019; Salfer et al., 2019). These studies have not reported the distribution of seasonality observed in calving pattern and milk production among herds. This may be useful to management planning and decision-making, because seasonality in calving patterns and milk production changes cash flows throughout the year. Furthermore, seasonality in milk production can result in supply and demand imbalances, which are costly (Washington et al., 2002).

Therefore, our objectives were (1) to describe the distribution of seasonality in calving pattern and milk production among herds in the United States, (2) to compare SW and LP ratios for calving pattern and milk production, (3) to quantify the effects of a seasonal calving pattern, parity, and percentage of dry cows on seasonality of milk production, and (4) to describe the association between seasonality in calving pattern and milk production for different herd sizes and average daily milk production per cow. Our hypothesis was that LP ratios calculated from sinusoidal models were better able to capture seasonality than SW ratios.

\section{MATERIALS AND METHODS}

\section{Data Source and Edits}

We obtained DHIA lactation records from Dairy Records Management Systems (DRMS, Raleigh, NC). Our study was a cross-sectional study for 2015. Therefore, we used test-day milk production lactation records from lactations from November 2011 to December 2015. To quantify seasonality of calving patterns, only calvings in 2015 were used. Before editing, our data set contained 1,345,509 calvings and 2,285,938 lactation records.

We calculated the number and the percentage of lactating and dry cows per day for each herd, and each herd's average size as the sum of the number of milking and dry cows. Dry dates were either reported or calculated. If a dry-off date was reported but a next calving date was not, we counted the number of days dry from the cow's dry-off date until her last day in the herd. If a dry-off date was not reported but a next calving date was reported, we assumed a dry period of 60 d. If neither a dry-off date nor a next calving date were reported, we used the cow's lactation length from the day she calved until her last day in the herd. 
To quantify seasonality in calving pattern, we summarized our calving data in 14-d periods (period 1: January 1 to January 14; period 2: January 15 to January 28 , and so forth). The purpose of creating these periods greater than $1 \mathrm{~d}$ was to avoid convergence problems with our logistic regression models, especially for small herds. Therefore, the time step of our calving model was 14-d periods, and a year was composed of 26 periods and 1 additional day, which was excluded from our analysis. For the calving pattern analysis, winter was defined as the 14-d periods 1 to 6 (January 1 to March 25), and summer was from period 13 to period 18 (June 18 to September 9). To quantify seasonality in milk production per (lactating) cow per day, the time step in our models was $1 \mathrm{~d}$. For milk production, we used the meteorological definition of season: winter was defined as the time from January 1 to March 30, and summer was from July 1 to September 30 (NOAA, 2017). These definitions allowed us to have winter and summer completed within the 2015 calendar year.

Herds were classified by 1 of 3 herd sizes according to the average number of cows in 2015, following the herd size classification of USDA-APHIS (2014). Small herds had a maximum of 99 cows. Medium-sized herds had from 100 to 499 cows, and large herds had 500 cows or more.

We divided the average number of cows present in January 2015 by the average number of cows present in January 2016 for each herd. If the ratio was less than 0.8 or greater than 1.2 (herd size was increasing or decreasing, respectively), the herd was excluded from our data set, due to the effect of the change in the number of cows on the measures of seasonality for that herd. We also excluded observations from herds with fewer than 50 cows (annual average) and those with fewer than 50 calvings per year. We excluded daily milk production less than 0.1 and larger than $150 \mathrm{~kg}$. Lactation records with no lactation number and herds with fewer than 6 test-days in a year were also excluded. A total of 54,212 calvings (4\%) and 387,497 (17\%) lactation records were excluded. The final data set included 1,898,445 lactation records from 5,200 herds, and 1,291,297 calvings from 5,292 herds, from 41 states. We used the total number of herds per state in 2015 (USDA-ERS, 2019) to calculate the percentage of herds per state present in our data set.

\section{Calving Pattern Model}

We used logistic regression models with a Poisson distribution with sine and cosine functions to describe the seasonality in calving patterns, with period of the year as the frequency for the geometric functions (Schukken et al., 1993; Stolwijk et al., 1999). We ran 1 model per herd, with the number of calvings per period as the dependent variable. We used PROC GENMOD with a log link (SAS 9.4; SAS Institute Inc., Cary, NC) to run the following model:

$$
y_{t}=\alpha+\beta_{1} \operatorname{sine}\left(\frac{2 \pi t}{26}\right)+\beta_{2} \operatorname{cosine}\left(\frac{2 \pi t}{26}\right)+e_{t},
$$

where $y_{t}$ is the number of calvings per period $t$, and $t$ is the period of the year, $\pi=3.14159, \alpha$ is the intercept, $\beta_{1}$ and $\beta_{2}$ are the parameters of the sine and cosine terms, and $e_{t}$ is the residual. We used the intercept $(\alpha)$ and sine and cosine parameters $\left(\beta_{1}, \beta_{2}\right)$ from Equation [1] to predict the number of calvings per period per herd (NCALVING).

\section{Milk Production Models}

Seasonality in milk production per cow per day might be explained by the percentage of cows dry in a herd, the DIM and parity of cows (West, 2003; Salfer et al., 2019), and a direct effect of climate or endogenous circannual rhythm. Therefore, we modeled milk production per lactating cow per day using test-day milk production records. We used the same approach for modeling seasonality in calving patterns, but with day of the year describing the frequency for the geometric functions. Models were adjusted (ADJ) or not adjusted (NO) for test-day DIM and for the interaction between parity (primiparous or multiparous) and DIM to account for a seasonal calving pattern and parity, respectively. We ran each model per herd, with individual test-day milk production as the dependent variable. Cow was included as a random effect in both models. We used PROC MIXED to run the models.

The non-adjusted model (NO) was as follows:

$$
y_{i t}=\alpha+\beta_{1} \operatorname{sine}\left(\frac{2 \pi t}{365.25}\right)+\beta_{2} \operatorname{cosine}\left(\frac{2 \pi t}{365.25}\right)+\operatorname{cow}_{i}+e_{i t},
$$

where $y_{i t}$ is test-day milk production per day for each lactating cow $i$ in the herd, $t$ is the day of the year of the test day ( 1 to 365 ), $\alpha$ is the intercept, $\beta_{1}$ and $\beta_{2}$ are the parameters of the sine and cosine terms, and $e_{i t}$ is the residual.

The adjusted model (ADJ) with the functional form that described the behavior of milk production by DIM and parity was 


$$
\begin{aligned}
& y_{i t}=\alpha+\beta_{1} \text { sine }\left(\frac{2 \pi t}{365.25}\right)+\beta_{2} \text { cosine }\left(\frac{2 \pi t}{365.25}\right) \\
& +\beta_{3} \text { prim } \times \text { DIM }+\beta_{4} \text { prim } \times \text { DIM }{ }^{2}+\beta_{5} \text { prim } \times \log (D I M) \\
& +\beta_{6} \text { multi } \times D I M+\beta_{7} \text { multi } \times D I M^{2}+\beta_{8} \text { multi } \times \log (D I M) \\
& + \text { cow }_{i}+e_{i t},
\end{aligned}
$$

where $y_{i t}, t, \alpha, \beta_{1}$, and $\beta_{2}$ were as earlier described, and $\beta_{3}, \beta_{4}, \beta_{5}, \beta_{6}, \beta_{7}$, and $\beta_{8}$ are the parameters of the fixed covariates DIM and parity (primiparous, prim, or multiparous, multi), and $e_{i t}$ is the residual. The functional form uses of DIM, DIM ${ }^{2}$, and $\log$ (DIM) was chosen because they fitted lactations curves well (data not shown). We used the model parameters to predict non-adjusted (MILKWET-NO) and adjusted (MILKWET-ADJ) milk production per lactating cow per day. We multiplied these predicted values by the percentage of lactating cows in the herd per test day $t$ to obtain the average milk production per cow per day. To smooth out the resulting data at the herd level, we used PROC REG, with sine and cosine functions as response variables, to obtain milk production per cow per day adjusted for DIM and parity (MILKALL-ADJ) or not adjusted (MILKALL-NO). A representation of the original data, the seasonality in dry cows, and the predictions from the models for 1 herd for MILKALLNO and MILKALL-ADJ is shown in Supplemental Figure S1 (https://doi.org/10.3168/jds.2019-18138). Finally, we calculated the annual daily milk production per cow per herd (annual MILKALL-NO) to determine the effects of the level of milk production on the seasonality measures.

\section{Measures of Seasonality}

Low-to-Peak Ratio. For each herd, we calculated the periods (for NCALVING) and day of the year (for MILKALL) of the maximum (peak) and minimum (low) using the parameters from the sine and cosine functions (Stolwijk et al., 1999). A detailed description of the calculations is provided in Supplemental File S1 (https://doi.org/10.3168/jds.2019-18138). Based on the dates of the nadir and peak, annual LP ratios of NCALVING, MILKALL-NO, and MILKALL-ADJ were calculated according to the following formula, and were measures of maximum seasonality:

$$
\mathrm{LP}=\frac{\hat{y}(\text { tlow })}{\hat{y}(\text { tpeak })},
$$

where LP is the low-to-peak ratio, $\hat{y}$ is the predicted value on the day (for MILKWET and MILKALL) or period (for NCALVING) of the year, and tlow or tpeak are the days or periods when the lowest and highest values were observed, respectively.

Summer-to-Winter Ratio. We used the observed number of calvings per period and the average observed test-day milk production per lactating cow multiplied by the percentage of lactating cows in each test day to calculate the SW ratios of calving pattern and milk production per cow according to this formula:

$$
S W=\frac{\frac{\sum_{s i}^{s f} y_{t}}{S_{\text {length }}}}{\frac{\sum_{w i}^{w f} y_{t}}{W_{\text {length }}}},
$$

where $y_{t}$ is the observed number of calvings or test-day milk production per cow per day, $t$ is period or test day, $s i$ is the beginning of the summer, $s f$ is the end of summer, $S_{\text {length }}$ is the duration of the summer in days or periods, wi is the beginning of winter, $w f$ is the end of the winter, and $W_{\text {length }}$ is the duration of the winter in days or periods.

In summary, we calculated 7 measures of seasonality per herd: SW ratio of the calving pattern, LP ratio of NCALVING, SW ratio of milk production, LP ratio of MILKWET-NO, LP ratio of MILKWET-ADJ, LP ratio of MILKALL-NO, and LP ratio of MILKALL-ADJ.

\section{Seasonality Explained by Covariates}

We calculated the percentage change in LP ratios calculated from non-adjusted and adjusted models for MILKALL to investigate the effect of adjusting for DIM and parity:

$$
\begin{gathered}
(1-\text { LPratio MILKALL-NO) } \\
C H A N G E A L L=\frac{-(1-\text { LPratio } M I L K A L L-A D J)}{1-\text { LPratio MILKALL-NO }} \times 100,
\end{gathered}
$$

where LP ratio was calculated using Equation [4]. This measure shows the percentage of seasonality explained by the covariates. Additionally, to measure the change in LP ratios by the percentage of dry cows in the herd, we calculated the difference between the LP ratio of MILKALL-ADJ and the LP ratio of MILKWET-ADJ: 


$$
\begin{aligned}
& (1-L P \text { ratio MILKALL-ADJ) } \\
& \text { CHANGEDR } Y=\frac{-(1-L P \text { ratio MILKWET }-A D J)}{1-\text { LP ratio MILKALL-ADJ }} \times 100 \text {. }
\end{aligned}
$$

\section{Analysis of Associations Among Seasonality Measures, Herd Size, and Daily Milk Production per Lactating Cow}

We measured the correlation between the SW ratios of calving pattern and milk production and LP ratios of NCALVING and MILKALL, and the annual MILKALL-NO. All correlation analyses were conducted using PROC CORR of SAS 9.4. In addition to correlations, we used univariate ANOVA (PROC GLM) to test for differences between SW ratio of calving pattern and milk production, and LP ratios of NCALVING and MILKALL-ADJ according to herd sizes, and annual MILKALL-NO. We used Levene's test for equality of variance to account for heterogeneous variance between groups. Pairwise comparisons (PROC T-TEST) were used to compare the LP ratios of MILKALL-NO and MILKALL-ADJ by state. Significance was declared at $P \leq 0.05$. We used PROC UNIVARIATE and PROC MEANS to describe the distribution of SW and LP ratios.

\section{RESULTS}

The number of herds in our data set, test-day average milk production per lactating cow, and average herd size per state for 2015 are shown in Table 1. Our final data set represented $13 \%$ of all herds in the United States in 2015. In our data, $49 \%$ of the herds were small, $43 \%$ were medium, and $9 \%$ were large. The 24 states with at least $15 \%$ of their herds represented in our data set (Table 1) summed to 4,380 herds for the milk production analysis, or $84 \%$ of all the herds in our data set.

\section{Seasonality Measures and Distribution Across the United States}

The overall median values for SW of calving pattern and LP ratio of NCALVING were 1.07 and 0.61 , respectively (Table 2). The overall median value of SW ratio of test-day milk production was 0.96 , the LP ratio of MILKALL-NO was 0.88 , and the LP ratio of MILKALL-ADJ was 0.90 (Table 2).

Variations in seasonality ratios were large within all states. The most seasonal states for NCALVING were in the southern part of the US (Figure 1). Based on median values, New Jersey was the least seasonal state for SW ratio of calving pattern (median 1.00, interquartile range 0.65 to 1.20 ), and Michigan was the least seasonal for LP ratio of NCALVING (median 0.68, interquartile range 0.55 to 0.78). South Carolina was the most seasonal state for SW ratio of calving pattern (median 0.65, interquartile range 0.39 to 0.86), and Louisiana for LP ratio of NCALVING (median 0.18, interquartile range 0.12 to 0.49 ). For milk production, southern states were the most seasonal as well, both for SW of milk production and for LP ratios of MILKALLNO and MILKALL-ADJ (Figure 2). The least seasonal state for LP ratio was Maine (LP ratio of MILKALLNO median 0.91, interquartile range 0.86 to 0.93 ; and LP ratio of MILKALL-ADJ median 0.92, interquartile range 0.89 to 0.95$)$. The most seasonal state for milk production was Louisiana (LP ratio of MILKALL-NO median 0.61, interquartile range 0.57 to 0.66 ; and LP ratio of MILKALL-ADJ median 0.67, interquartile range of 0.60 to 0.74 ).

\section{Distribution of the Dates When Peak and Nadir Values Were Observed}

Peaks and nadirs often did not occur in the winter and summer. The median 14-d period when the peak for NCALVING was observed was from August 26 to September 8 (Figure 3A). The median period of nadir for NCALVING was in the spring from May 6 to May 19 (Figure 3B). The overall median peak day for MILKALL-NO was April 19, and it reached a nadir median date on September 16. The median peak day for MILKALL-ADJ was April 29 (Figure 3C). The median nadir date was October 1 (Figure 3D).

\section{Seasonality and Herd Size}

Small herds showed consistently lower LP ratios of NCALVING and MILKALL $(P<0.0001)$. The SW ratios for calving pattern and milk production also varied $(P<0.0001)$ by herd size, but the differences were small (Table 2).

For NCALVING, small herds had a median LP ratio of 0.56 , versus 0.65 for medium herds and 0.75 for large herds. For MILKALL, the same pattern was observed: small herds had a lower median LP ratio of MILKALLADJ than large herds by $[(1-0.89)-(1-0.92)] /$ $(1-0.89)=27 \%$.

The SW ratios consistently underestimated the maximum seasonality for calving pattern and milk production for all herd sizes (Table 2). As shown in Table 2 , the median SW ratio for calving pattern for small 
herds was 1.06 (6 percentage points seasonal), whereas the median LP ratio of NCALVING was 0.56.

\section{Seasonality in Milk Production Explained by Calving Pattern, Parity, and Percentage of Dry Cows}

Overall, adjusting for DIM and parity increased the LP ratio of MILKALL (Equation [6]), for $66 \%$ $(3,422 / 5,200)$ of the herds, by a median increase of $8.9 \%$. Thus, the unexplained seasonality decreased in these herds. Among the herds for which the LP ratio of MILKALL increased (Figure 4A), the median increase was $18 \%$. The greatest fraction of herds for which the LP ratio increased after adjustments (96\%) was in Florida, with a median increase of $17 \%$.
The overall median increase in LP ratio of MILKALL when adjusting for the percentage of dry cows, DIM, and parity (Equation [7]) was $30.7 \%$, for $72.9 \%$ of the herds. Among the herds for which the LP ratio of MILKALL increased, the median increase value was $21.8 \%$ (Figure 4B). The greatest increases in seasonality due to percentage of dry cows were observed in Florida (92\% of herds, median increase of $47.7 \%$ ) and Texas ( $94 \%$ of herds, median increase of $41.2 \%$ ).

\section{Associations Between Measures of Seasonality, and Average Milk Produced per Cow}

Figure 5A shows the scatterplot of the SW ratios of calving pattern and LP ratios of NCALVING, with a

Table 1. Number of herds, average milk production, average herd size, and percentage of herds in the data set, by state ${ }^{1}$

\begin{tabular}{|c|c|c|c|c|c|c|c|}
\hline \multirow[b]{2}{*}{ State } & \multicolumn{2}{|c|}{ Number of herds } & \multirow{2}{*}{$\begin{array}{c}\text { Average milk } \\
\text { production } \\
(\mathrm{kg} / \text { cow per day) }\end{array}$} & \multicolumn{2}{|c|}{$\begin{array}{l}\text { Average herd size } \\
\text { (number of cows) }\end{array}$} & \multicolumn{2}{|c|}{$\begin{array}{l}\text { Percentage of herds } \\
\text { in the data set }\end{array}$} \\
\hline & $\begin{array}{l}\text { Milk } \\
\text { analysis }\end{array}$ & $\begin{array}{l}\text { Calving } \\
\text { analysis }\end{array}$ & & $\begin{array}{c}\text { Milk } \\
\text { analysis }\end{array}$ & $\begin{array}{l}\text { Calving } \\
\text { analysis }\end{array}$ & $\begin{array}{l}\text { Milk } \\
\text { analysis }\end{array}$ & $\begin{array}{l}\text { Calving } \\
\text { analysis }\end{array}$ \\
\hline Alabama & 4 & 6 & 25.0 & 116 & 127 & 11 & 17 \\
\hline California & 7 & 8 & 31.8 & 2,419 & 2,381 & 1 & 1 \\
\hline Colorado & 2 & 2 & 25.6 & 5,983 & 5,983 & 2 & 2 \\
\hline Connecticut $^{3}$ & 31 & 32 & 31.6 & 238 & 244 & 28 & 29 \\
\hline Delaware $^{3}$ & 13 & 13 & 31.1 & 189 & 189 & 43 & 43 \\
\hline Florida $^{3}$ & 25 & 26 & 29.8 & 912 & 892 & 23 & 24 \\
\hline Georgia $^{3}$ & 52 & 54 & 29.1 & 362 & 353 & 29 & 30 \\
\hline Illinois $^{3}$ & 168 & 172 & 31.9 & 153 & 157 & 27 & 27 \\
\hline Indiana & 102 & 102 & 32.0 & 191 & 191 & 10 & 10 \\
\hline Iowa $^{3}$ & 245 & 248 & 33.7 & 191 & 190 & 20 & 21 \\
\hline Kansas $^{3}$ & 68 & 67 & 30.5 & 154 & 156 & 23 & 23 \\
\hline Kentucky & 42 & 43 & 31.5 & 202 & 199 & 7 & 7 \\
\hline Louisiana $^{3}$ & 15 & 18 & 22.4 & 132 & 146 & 16 & 19 \\
\hline Maine $^{3}$ & 37 & 36 & 30.3 & 194 & 206 & 15 & 14 \\
\hline Maryland $^{3}$ & 86 & 88 & 30.5 & 178 & 172 & 22 & 22 \\
\hline Massachusetts $^{3}$ & 26 & 26 & 28.7 & 109 & 110 & 19 & 19 \\
\hline Michigan $^{3}$ & 271 & 276 & 33.5 & 268 & 276 & 15 & 16 \\
\hline Minnesota $^{3}$ & 748 & 768 & 32.6 & 165 & 164 & 23 & 24 \\
\hline Missouri & 72 & 72 & 27.9 & 122 & 122 & 7 & 7 \\
\hline Mississippi & 6 & 10 & 32.5 & 222 & 161 & 9 & 14 \\
\hline North Carolina ${ }^{3}$ & 54 & 57 & 30.1 & 209 & 211 & 28 & 30 \\
\hline North Dakota & 9 & 11 & 31.3 & 306 & 278 & 11 & 14 \\
\hline Nebraska $^{3}$ & 35 & 37 & 31.5 & 278 & 296 & 23 & 24 \\
\hline New York ${ }^{3}$ & 758 & 767 & 32.0 & 243 & 244 & 17 & 17 \\
\hline New Hampshire ${ }^{3}$ & 31 & 35 & 30.6 & 170 & 163 & 28 & 32 \\
\hline New Jersey ${ }^{3}$ & 15 & 15 & 30.3 & 119 & 119 & 27 & 27 \\
\hline Ohio & 266 & 272 & 31.9 & 193 & 193 & 11 & 11 \\
\hline Oklahoma & 14 & 15 & 26.5 & 181 & 180 & 9 & 9 \\
\hline Pennsylvania ${ }^{3}$ & 1,279 & 1,285 & 31.6 & 121 & 122 & 19 & 20 \\
\hline South Carolina ${ }^{3}$ & 13 & 16 & 28.3 & 196 & 228 & 22 & 27 \\
\hline South Dakota ${ }^{3}$ & 41 & 41 & 33.1 & 357 & 357 & 18 & 18 \\
\hline Tennessee $^{3}$ & 49 & 48 & 27.9 & 156 & 156 & 18 & 18 \\
\hline Texas & 54 & 55 & 27.1 & 458 & 452 & 14 & 14 \\
\hline Vermont $^{3}$ & 120 & 124 & 31.3 & 233 & 243 & 15 & 15 \\
\hline Virginia $^{3}$ & 200 & 202 & 30.9 & 190 & 192 & 34 & 35 \\
\hline West Virginia & 10 & 10 & 28.2 & 108 & 108 & 13 & 13 \\
\hline Wisconsin & 228 & 231 & 34.5 & 230 & 230 & 3 & 3 \\
\hline
\end{tabular}

${ }^{1}$ The states of Arkansas, New Mexico, Montana, and Rhode Island had 1 herd each represented in our data set.

${ }^{2}$ Percentage of herds: number of herds in our data set compared with number of herds reported by USDA-ERS (2019).

${ }^{3}$ States from which we have at least $15 \%$ of their herds represented in our data set for milk analysis. Total number of herds for milk analysis was 5,200 , and total number of herds for calving analysis was 5,292. 
Table 2. Overall distribution of seasonality ratios of calving pattern and milk production per cow per day by herd size in 2015

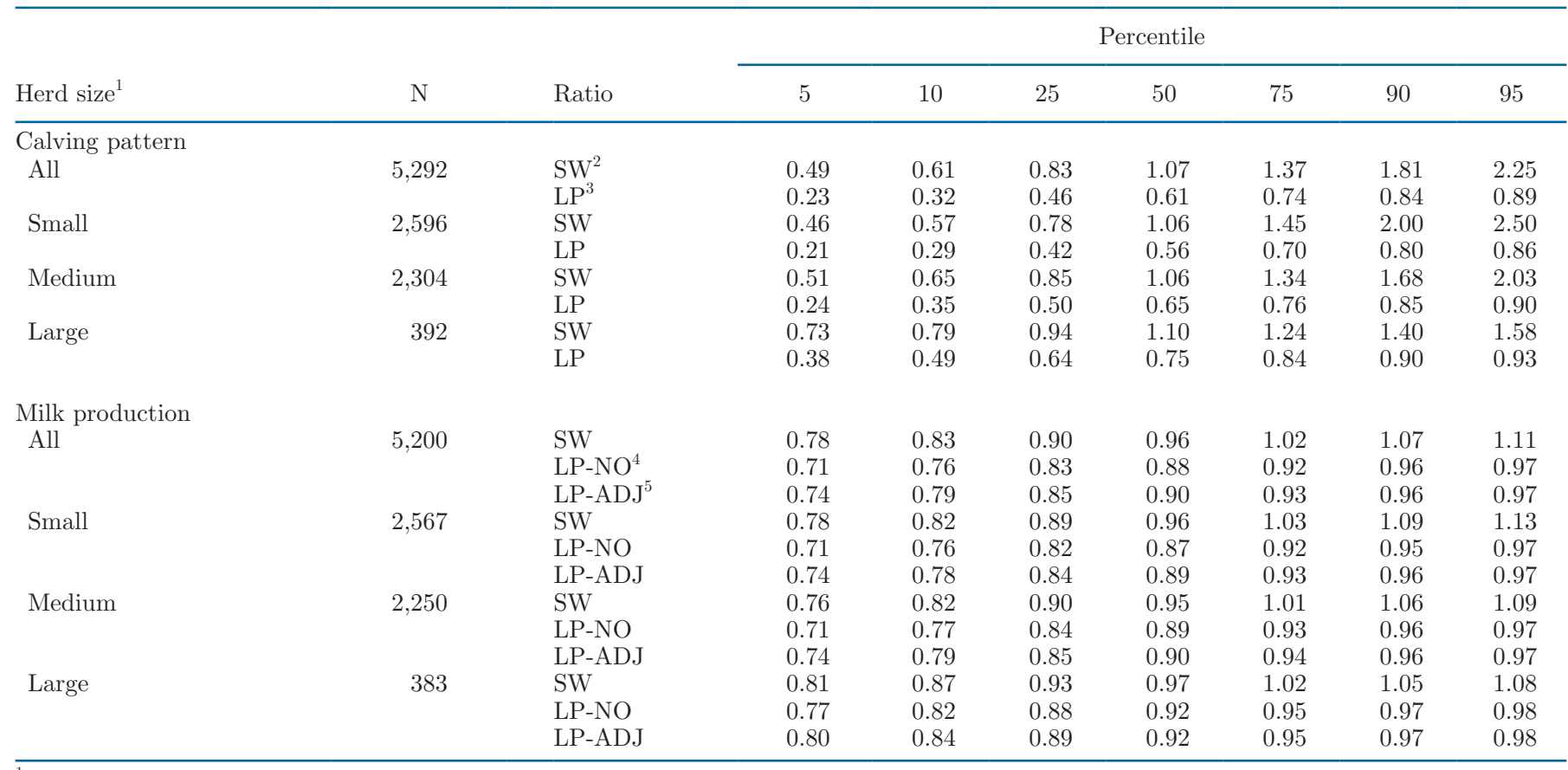

${ }^{1}$ Small herds had a maximum of 99 cows, medium herds had from 100 to 499 cows, and large herds had 500 cows or more.

${ }^{2} \mathrm{SW}=$ summer-to-winter ratio.

${ }^{3} \mathrm{LP}=$ low-to-peak ratio.

${ }^{4} \mathrm{LP}-\mathrm{NO}=$ low-to-peak ratio not adjusted for DIM and parity.

${ }^{5} \mathrm{LP}-\mathrm{ADJ}=$ low-to-peak ratio adjusted for DIM and parity.

correlation of $-0.21(P<0.0001)$. Figure $5 \mathrm{~B}$ shows the SW ratios of milk production and LP ratios of MILKALL-ADJ. The correlation was $0.55(P<0.0001)$. The correlation between LP ratio of MILKALL-NO and LP ratio of MILKALL-ADJ was $0.91(P<0.0001)$, showing that even after adjustments the most seasonal herds continue to be seasonal. The correlation between LP ratio of NCALVING and LP ratio of MILKALL-ADJ was $0.45(P<0.0001$; Supplemental Figure S2, https: //doi.org/10.3168/jds.2019-18138), and the correlation between the SW ratio of calving pattern and the SW ratio of milk production was $-0.14(P<0.0001)$.

Less-seasonal herds had a higher annual MILKALLNO $(P<0.0001)$. For every increase of 0.01 of the LP ratio of MILKALL-ADJ, annual MILKALL-NO increased by $0.22 \mathrm{~kg}$. The correlation between the LP ratio of NCALVING and annual MILKALL-NO was $0.29(P<0.0001$; Supplemental Figure S3, https://doi .org/10.3168/jds.2019-18138), and between LP ratio of MILKALL-ADJ and annual MILKALL-NO was 0.34 $(P<0.0001$; Supplemental Figure S4, https://doi.org/ 10.3168/jds.2019-18138).

\section{DISCUSSION}

\section{Modeling Seasonality with Trigonometric Functions}

The first objective of this study was to describe the distribution of seasonality in the patterns of calving and milk production per cow across the United States. We have reported a great variation in seasonality measured by SW and LP ratios, with greater variation observed in the southern states. This can be explained by a higher degree of heat stress experienced by these states (Ferreira et al., 2016). Similar results were reported by Salfer et al. (2020), who found greater amplitudes of milk, milk fat, and milk yield in states in the southern United States (Florida and Texas). Additionally, Guinn et al. (2019) have reported SW ratios of ECM across different regions of the United States, with a narrower range of variation (from 0.87 for herds in the Southern Plains region to 0.94 for herds in the Northeast and Midwest). Oseni et al. (2003) reported a greater LP ratio for calving pattern across the United States (0.30), but the authors used different monthly calving data and values per state than ours. 
We used a model that would allow us to adjust for covariates that can explain part of the seasonal pattern observed in these variables. The generalized linear models with trigonometric functions used in this study are flexible, allow for the adjustment of covariates, and can accommodate different distributions of the response variable (Stolwijk et al., 1999; Fisman, 2007; Christiansen et al., 2012). In addition, the precise dates of the peak and the nadir can be calculated using the parameters of the sine and cosine functions of the model. It is possible to add multiple trigonometric functions with different frequencies of seasonality to model any frequency observed in the data (Stolwijk et al., 1999).

In our study, we assigned a single sinusoidal curve to capture the seasonal behavior of the farm data and the distribution of seasonality. For that, we assumed a
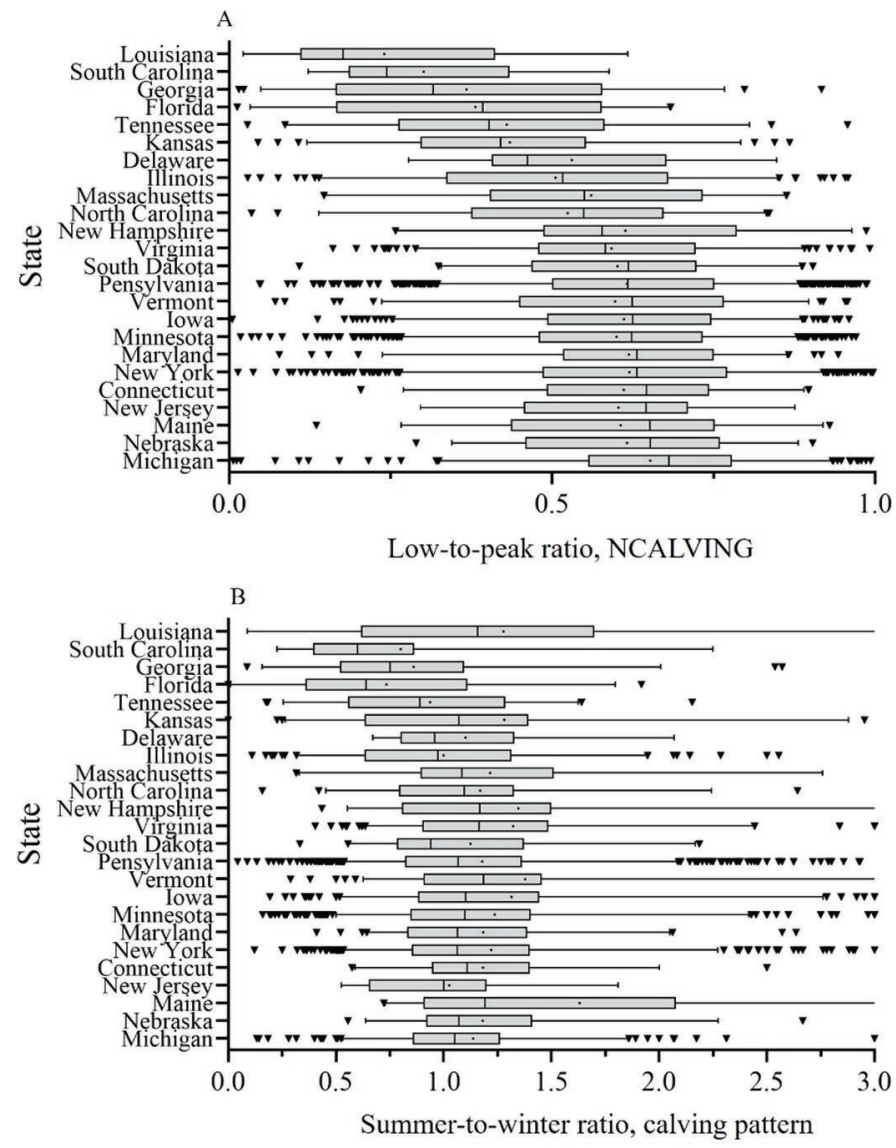

Figure 1. Distribution of seasonality of calving pattern per state measured by (A) low-to-peak ratio of the modeled number of calvings (NCALVING) and (B) summer-to-winter ratio of calving pattern for states with at least $15 \%$ of their herds in the data set. Gray boxes represent data between the 25 th and 75 th percentiles. Whiskers represent data between the 5th and 95th percentiles. Triangles are outliers. The vertical line within each box represents the median value. The dot within each box represents the mean value. period for the seasonal cycle of $365.25 \mathrm{~d}$; that is, one year. Salfer et al. (2019) showed that sinusoidal cycles following a yearly annual rhythm fit milk production well, but the goodness of fit varies according to herd
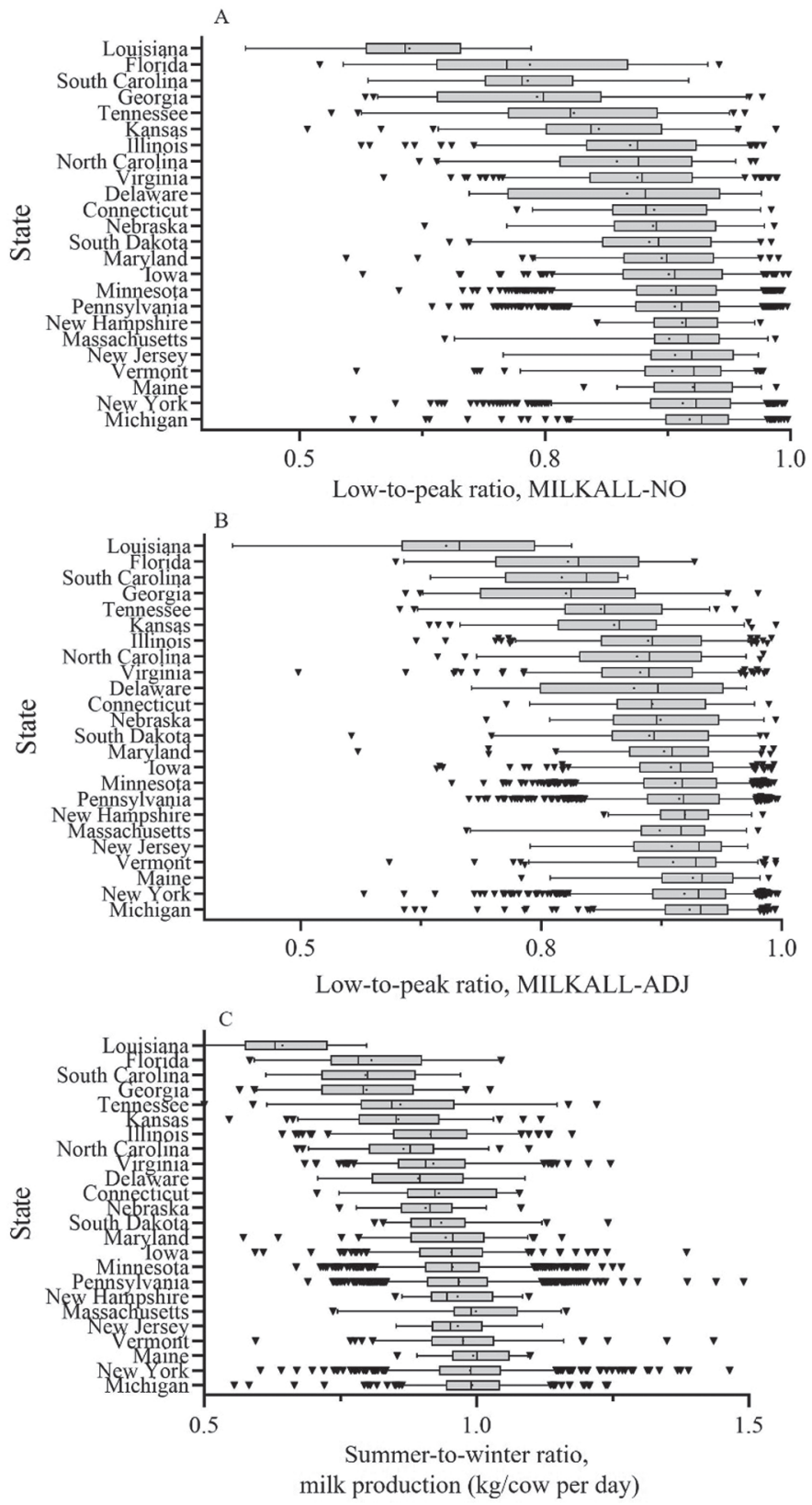

Figure 2. Distribution of seasonality of milk production per state measured by (A) low-to-peak ratio not adjusted for DIM and parity (MILKALL-NO), (B) low-to-peak ratio adjusted for DIM and parity (MILKALL-ADJ), and (C) summer-to-winter ratio of milk production. States with at least $15 \%$ of their herds in the data set are represented. Gray boxes represent data between the 25th and 75 th percentiles. Whiskers represent data between the 5th and 95th percentiles. Triangles are outliers. The vertical line within each box represents the median value. The dot within each box represents the mean value. 
and geographical location. In our study, it is possible that for some farms the cycles could be more or less frequent (for instance, bi-annual), or may not have a clear peak or nadir, or might have periods where the data are similar so that a sinusoidal pattern is not observed. For these herds, it is likely that the fit of the model was not ideal and could be improved by adding more sinusoidal curves in the model. The impossibility of running a herd-specific model per herd, and concern about not overfitting our data, led us to work with only 1 sinusoidal curve per herd. Nonetheless, this approach allowed us to both smooth the raw data and adjust directly for covariates. Additionally, the SW and LP ratios might use adjusted variables, such as standardized 150-d milk. However, such standardization is not as herd-specific as adding covariates to a model.

Risk factors for seasonality can also be studied if precise dates of the peak and nadir are identified. When seasonal milking price policies are in place as an effort to reduce seasonality in milk supply, management recommendations and economic analysis can benefit from knowledge about factors responsible for seasonality in specific herds or regions (Hall et al., 1987; Oltenacu et al., 1989). Furthermore, trends in seasonality in calving patterns and milk production, as well as for other variables can be studied across the years using the methodology presented in this work.
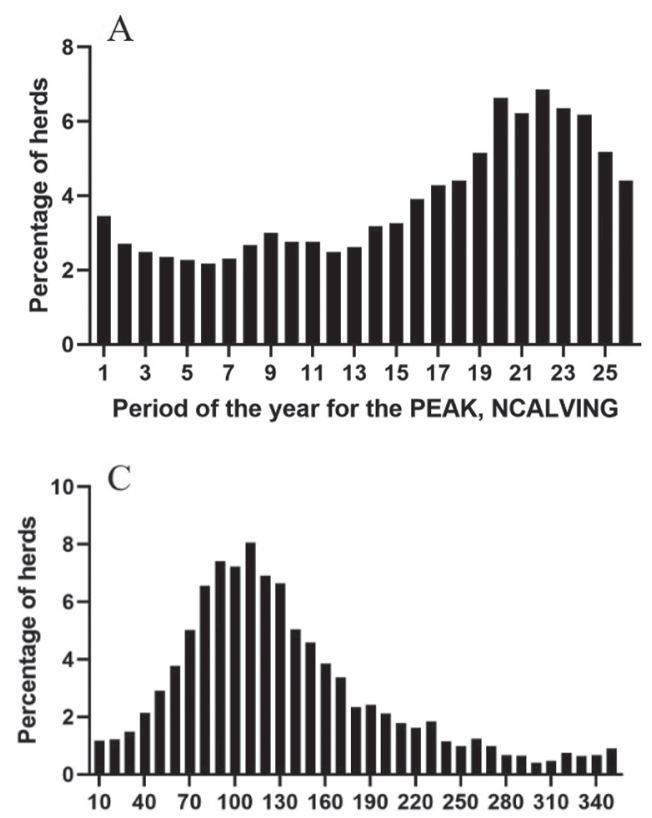

Day of the year for the PEAK ADJ, MILKALL (kg/cow per day)

\section{Comparison of SW and LP Ratios as Measures of Seasonality}

Our second objective was to compare the seasonality measures SW and LP ratios for patterns of calving and milk production in dairy herds across the United States. Summer-to-winter ratios were not fully able to capture the maximum seasonality in calving and milk production. The SW ratio is a straightforward, easyto-calculate index that has been used in the literature as a measure of seasonality (Flamenbaum and Galon, 2010; Guinn et al., 2019). One limitation associated with this measure is the inability to consider the moment of the peak and the nadir. In our study, the dates of the peaks and the nadirs did not always occur during winter or summer. Data from USDA-ERS (2020) on milk production by month show that the maximum and minimum volumes of milk produced in the United States occur during spring and fall, respectively. Salfer et al. (2019) reported similar dates for the peak of daily milk production for 8 out of the 11 herds they studied in Pennsylvania. To overcome this issue, some authors have calculated indexes similar to the SW ratio, defining the periods of peak and nadir of the variable based on their knowledge of the behavior of the variable, such as somatic cell count (e.g., Ferreira and De Vries, 2015). Other authors have used SW ratios, but their
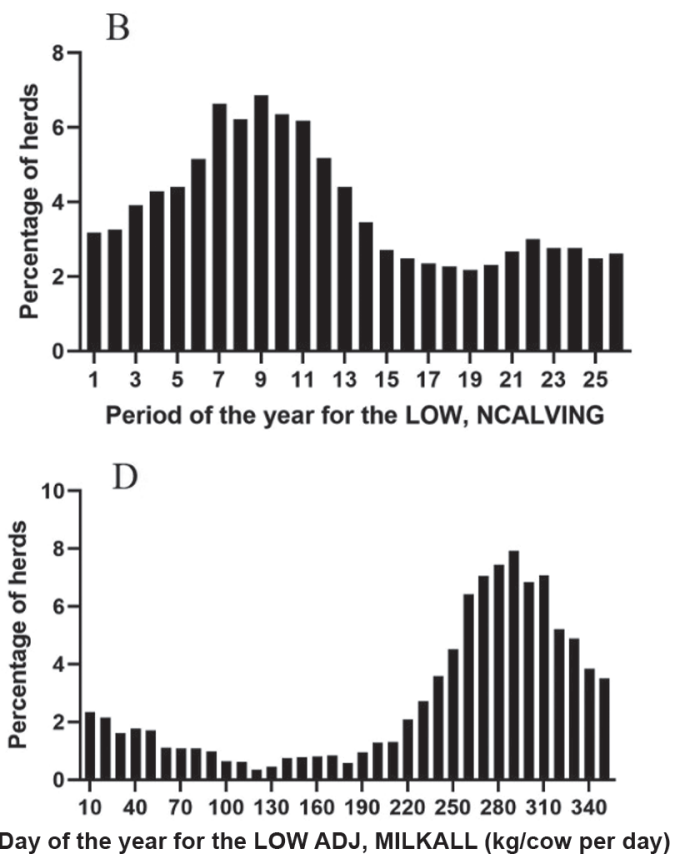

Figure 3. Distribution of the periods of the year when (A) the peak (PEAK, NCALVING) and (B) the nadir of predicted calvings (LOW, NCALVING) were observed. Distribution of the days of the year when (C) the peak (PEAK ADJ, MILKALL) and (D) the nadir values for predicted milk production per cow per day adjusted for DIM and parity (LOW ADJ, MILKALL) were observed. 

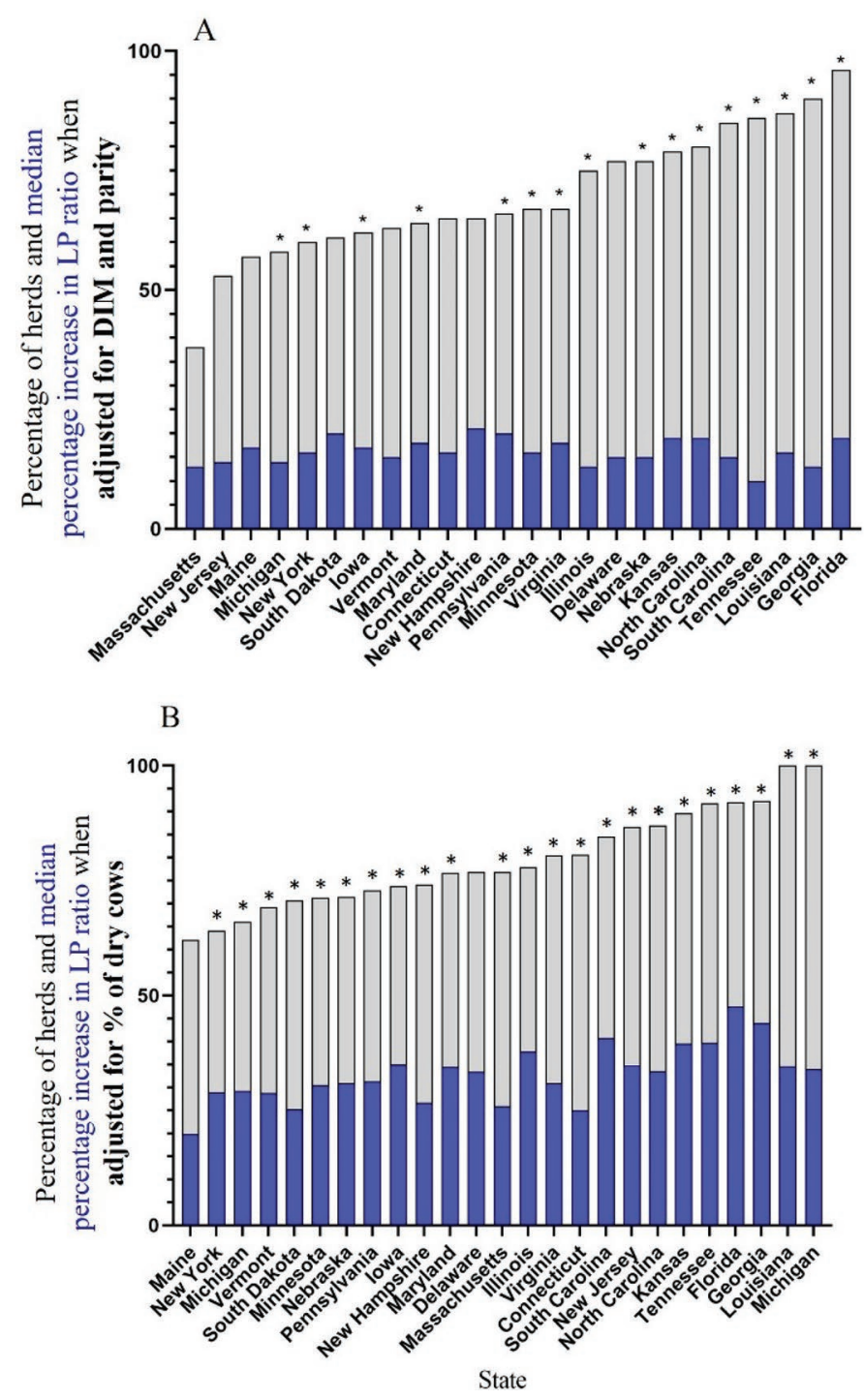

Figure 4. Percentage of herds by state (A) for which the low-topeak (LP) ratio of predicted milk production per cow per day increased when adjusted for parity and DIM and (B) for which the LP ratio increased after adjusting for percentage of dry cows. ${ }^{*}$ represent states in which average increases were different from $0(P \leq 0.05)$. States shown had at least $15 \%$ of their herds in the data set. Gray bars represent the percentage of herds in each state for which the LP ratio increased after adjusting for DIM and parity (A) and for which the LP ratio increased after adjusting for percentage of dry cows (B). Blue bars represent the median percentage increase in LP ratio in each state.

definitions of summer and winter may vary according to the dates of data collection (Cazer et al., 2013). These variations in the definition of season and in the methods of measuring seasonality are a challenge for comparison of the amount of seasonality across studies (Ferreira and De Vries, 2015).

The SW ratio is a ratio of averages, so the seasonality measured by an SW ratio will be less than the seasonality measured by an LP ratio. For calculations of LP ratios, one data point (lowest value) is divided by another unique data point (highest value). One possible approach to make SW and LP ratios more comparable would be to calculate the averages for the $45 \mathrm{~d}$ before and after the date of the nadir and divide this by the averages of the $45 \mathrm{~d}$ before and after the date of the peak. However, even when we averaged out the predicted values for NCALVING and MILKALL for 45 $\mathrm{d}$ before and after the days of the peak and nadir (using an approach similar to that used to calculate SW ratios) and calculated new LP ratios, we observed that seasonality captured by LP ratios was still greater than when SW ratios were used for both NCALVING and MILKALL (data not shown). For instance, the overall median seasonality for MILKALL measured by SW ratio was 0.96 . The LP ratio of MILKALL-NO was 0.88 , with no change when LP ratio was calculated based on a 90-d average of MILKALL-NO (0.88). The correlations between SW ratio and the 90-d averaged LP ratio of MILKALL-NO increased from 0.54 (SW ratio and $\mathrm{LP}$ ratio of MILKALL-NO, $\mathrm{n}=5,200$ ) to 0.71 (SW ratio and LP ratio of MILKALL-NO averaged for $90 \mathrm{~d}$, $\mathrm{n}=1,850$ herds with $90 \mathrm{~d}$ around the dates of the peak and the nadir available in 2015). This illustration reinforces the limitation of SW ratios to capture maximum seasonality, especially when the peak and nadir do not fall in the middle of the summer and winter.

Other authors have used amplitude as a measure of seasonality (calculated from a linear model with 1 sinusoidal curve to describe season) and classified herds based on amplitude height (Olde Riekerink et al., 2007; Salfer et al., 2019). However, amplitude values are not comparable with the traditional SW ratios because they are in different scales. The use of LP ratios allows for numerical comparison, including comparison with the traditional SW ratio.

\section{Effects of Seasonal Calving Pattern, Parity, and Percentage of Dry Cows}

Our third objective was to quantify the effect of a seasonal calving pattern, parity, and percentage of dry cows on seasonality of milk production per cow per day. The most seasonal states in our data set are in the southern United States and experience the greatest number of heat stress days per year (Ferreira et al., 2016). Heat stress is one of the major components of seasonality in dairy farms (West, 2003). However, seasonality in reproductive performance (De Vries and Risco, 2005; Schüller et al., 2014, 2017) and management decisions (Oseni et al., 2003; DeJarnette et al., 2007) can lead to a seasonal calving pattern, with the greatest proportion of cows calving in the spring or late fall (Oseni et al., 2003; Chen et al., 2014; Shock 
et al., 2015). This seasonal calving pattern changes the dynamics of the average DIM and the percentage of dry cows of the herd, which concentrate cows in late stages of lactation during specific times of the year. When we adjusted our models for DIM, parity, and percentage of dry cows in the herd, the overall LP ratio increased substantially (by $30.7 \%$ ), demonstrating the influence of management decisions on seasonality. Recently, Salfer et al. (2019) showed evidence of an endogenous annual rhythm controlling milk production, and this may partially explain the remaining seasonality observed after adjustments were made.

\section{Associations Between Seasonality, Herd Size, and Level of Milk Production per Cow}

Our fourth objective was to quantify the association between seasonality measures $\mathrm{SW}$ and $\mathrm{LP}$ ratios of MILKALL, MILKALL-NO, NCALVING, and herd size. We observed that small herds were more seasonal than large herds for both NCALVING and MILKALL. This agrees with findings from other studies (Berry et al., 2006; Lukas et al., 2008; Ferreira and De Vries, 2015; Shock et al., 2015). Large herds have been reported as tending to invest more in cooling systems and to have better reproductive programs (Rodrigues et al., 2005), which can explain the difference observed. After adjustments, small herds had the greatest decrease in seasonality. Nonetheless, large herds still showed a degree of seasonality. As pointed out by Salfer et al. (2019), the remaining seasonality could be explained by endogenous annual rhythms, and individual variation could be maximized in small herds. Finally, we observed that herds with higher average daily milk production per cow were less seasonal for both NCALVING and
MILKALL. Different overall management, including cow cooling, can explain the observed difference.

\section{Limitations}

In this work, we grouped our calving data in 26 periods of $14 \mathrm{~d}$ each, which did not allow us to identify the unique days of the peak and the nadir of the number of calvings. Therefore, the maximum seasonality measured by LP ratios is slightly underestimated. Our first option was to model the number of calvings by day. We chose the period approach to summarize our data to overcome convergence issues of our models and because, for small herds, the daily approach was not feasible, as many days had no calvings at all.

We have used DHIA data provided by the DRMS (Raleigh, NC). As of 2017, DRMS was responsible for processing the milk test data of $71 \%$ and $49 \%$ of the herds and cows enrolled in the national DHI testing program in the United States (DRMS, 2020). The percent of herds that have their DHIA processed by DRMS varies from state to state. Therefore, our data set does not have a significant number of herds in regions such as the Northwest or Southwest of the United States. These usually larger herds were less represented in our data set and might have different patterns of seasonality.

\section{CONCLUSIONS}

The use of generalized linear models with geometric functions allows the smoothing of data, adjustments for covariates, and precise identification of the dates of the peaks and the nadirs of calvings and milk production. Low-to-peak ratios are better measures of seasonality
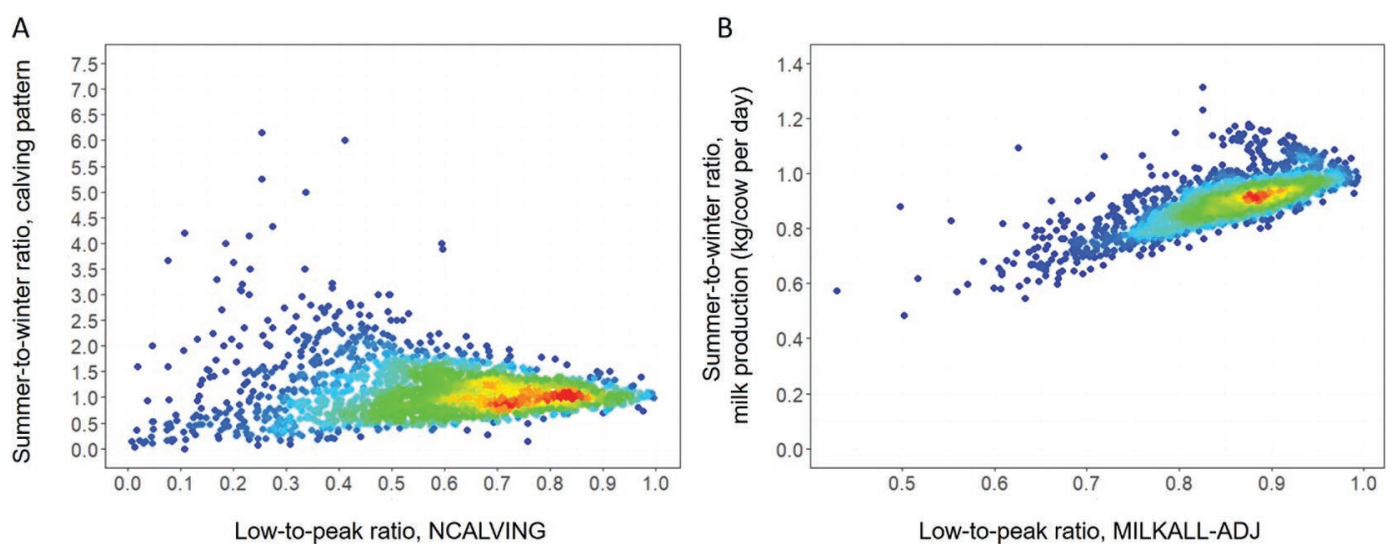

Figure 5. Scatterplots $(\mathrm{n}=5,200)$ of $(\mathrm{A})$ summer-to-winter $(\mathrm{SW})$ ratio of calving pattern and low-to-peak (LP) ratios for number of calvings (NCALVING; $\mathrm{r}=-0.21, P<0.0001 ; 89$ data points outside of the axis limits not shown), and (B) SW ratio of milk production and LP ratio for milk production per cow per day adjusted for DIM and parity (MILKALL-ADJ; $\mathrm{r}=0.55, P<0.0001$ ). Red and blue regions represent greater and lower concentrations of data points, respectively. 
than summer-to-winter ratios and can capture maximum seasonality. Seasonality in number of calvings and milk production is present across the United States, and states in the southern United States are more seasonal for calving pattern and milk production. Small herds and herds with a lower average daily milk production per cow are usually more seasonal than large herds and herds with higher production of milk per cow per year.

\section{ACKNOWLEDGMENTS}

Fernanda C. Ferreira thanks CAPES (Coordenacao de Aperfeicoamento de Pessoal de Nivel Superior), Brasilia, Federal District, Brazil, for financial support of her graduate studies. The authors also thank Dairy Records Management Systems (Raleigh, NC) for providing the DHIA data. The authors have not stated any conflicts of interest.

\section{REFERENCES}

Allore, H. G., P. A. Oltenacu, and H. N. Erb. 1997. Effects of season, herd size, and geographic region on the composition and quality of milk in the northeast. J. Dairy Sci. 80:3040-3049. https://doi.org/ 10.3168/jds.S0022-0302(97)76271-4.

Baumgard, L. H., and R. P. Rhoads. 2012. Ruminant Nutrition Symposium: Ruminant production and metabolic response to heat stress. J. Anim. Sci. 90:1855-1865. https://doi.org/10.2527/jas $.2011-4675$

Bernabucci, U., L. Basiricò, P. Morera, D. Dipasquale, A. Vitali, F. Piccioli Cappelli, and L. Calamari. 2015. Effect of summer season on milk protein fractions in Holstein cows. J. Dairy Sci. 98:18151827. https://doi.org/10.3168/jds.2014-8788.

Berry, D. P., B. O'Brien, E. J. O'Callaghan, K. O. Sullivan, and W. J. Meaney. 2006. Temporal trends in bulk tank somatic cell count and total bacterial count in Irish dairy herds during the past decade. J. Dairy Sci. 89:4083-4093. https://doi.org/10.3168/jds .S0022-0302(06)72453-5.

Cazer, C. L., R. M. Mitchell, K. M. Cicconi-Hogan, M. Gamroth, R. M. Richert, P. L. Ruegg, and Y. H. Schukken. 2013. Associations between Mycobacterium avium ssp. paratuberculosis antibodies in bulk tank milk, season of sampling and protocols for managing infected cows. BMC Vet. Res. 9:234. https://doi.org/10.1186/1746 $-6148-9-234$.

Chen, B., M. J. Lewis, and A. S. Grandison. 2014. Effect of seasonal variation on the composition and properties of raw milk destined for processing in the UK. Food Chem. 158:216-223. https://doi .org/10.1016/j.foodchem.2014.02.118.

Christensen, A. L., S. Lundbye-Christensen, and C. Dethlefsen. 2011. Poisson regression models outperform the geometrical model in estimating the peak-to-trough ratio of seasonal variation: A simulation study. Comput. Methods Programs Biomed. 104:333-340. https://doi.org/10.1016/j.cmpb.2011.07.016.

Christiansen, C. F., L. Pedersen, H. T. Sørensen, and K. J. Rothman. 2012. Methods to assess seasonal effects in epidemiological studies of infectious diseases - Exemplified by application to the occurrence of meningococcal disease. Clin. Microbiol. Infect. 18:963969. https://doi.org/10.1111/j.1469-0691.2012.03966.x.

De Vries, A. 2004. Economic value of delayed replacement when cow performance is seasonal. J. Dairy Sci. 87:2947-2958. https://doi .org/10.3168/jds.S0022-0302(04)73426-8.

De Vries, A., and C. A. Risco. 2005. Trends and seasonality of reproductive performance in Florida and Georgia dairy herds from 1976 to 2002. J. Dairy Sci. 88:3155-3165. https://doi.org/10.3168/jds .S0022-0302(05)72999-4.

DeJarnette, J. M., C. G. Sattler, C. E. Marshall, and R. L. Nebel. 2007. Voluntary waiting period management practices in dairy herds participating in a progeny test program. J. Dairy Sci. 90:10731079. https://doi.org/10.3168/jds.S0022-0302(07)71594-1.

DRMS (Dairy Records Management Systems). 2020. Service area. Accessed Mar. 1, 2020. https://www.drms.org/Support/About-Us.

Ferreira, F. C., and A. De Vries. 2015. Effects of season and herd milk volume on somatic cell counts of Florida dairy farms. J. Dairy Sci. 98:4182-4197. https://doi.org/10.3168/jds.2014-8695.

Ferreira, F. C., R. S. Gennari, G. E. Dahl, and A. De Vries. 2016. Economic feasibility of cooling dry cows across the United States. J. Dairy Sci. 99:9931-9941. https://doi.org/10.3168/jds.2016-11566.

Fisman, D. N. 2007. Seasonality of infectious diseases. Annu. Rev. Public Health 28:127-143. https://doi.org/10.1146/annurev .publhealth.28.021406.144128.

Flamenbaum, I., and E. Ezra. 2007. "The Summer to Winter performance ratio" as a tool for evaluating heat stress relief efficiency of dairy herds. J. Dairy Sci. 85(Suppl. 1):605.

Flamenbaum, I., and N. Galon. 2010. Management of heat stress to improve fertility in dairy cows in Israel. J. Reprod. Dev. 56(Suppl.):S36-S41. https://doi.org/10.1262/jrd.1056S36.

Guinn, J. M., D. T. Nolan, P. D. Krawczel, C. S. Petersson-Wolfe, G. M. Pighetti, A. E. Stone, S. H. Ward, J. M. Bewley, and J. H. C. Costa. 2019. Comparing dairy farm milk yield and components, somatic cell score, and reproductive performance among United States regions using summer to winter ratios. J. Dairy Sci. 102:11777-11785. https://doi.org/10.3168/jds.2018-16170.

Hall, S. C., P. A. Oltenacu, and R. A. Milligan. 1987. Returns to dairy producers under different seasonal production patterns. Research Bull. Department of Agriculture and Economics, Cornell University, Ithaca, NY.

Lukas, J. M., J. K. Reneau, C. Munoz-Zanzi, and M. L. Kinsel. 2008. Predicting somatic cell count standard violations based on herd's bulk tank somatic cell count. Part II: Consistency index. J. Dairy Sci. 91:433-441. https://doi.org/10.3168/jds.2007-0648.

NOAA (National Oceanic and Atmospheric Administration), National Centers for Environmental Information. 2017. Meteorological versus astronomical seasons. Accessed Feb. 8, 2019. https://www.ncei .noaa.gov/news/meteorological-versus-astronomical-seasons.

Olde Riekerink, R. G. M., H. W. Barkema, and H. Stryhn. 2007. The effect of season on somatic cell count and the incidence of clinical mastitis. J. Dairy Sci. 90:1704-1715. https://doi.org/10.3168/jds .2006-567.

Oltenacu, P. A., T. R. Smith, and H. M. Kaiser. 1989. Factors associated with seasonality of milk production in New York state. J. Dairy Sci. 72:1072-1079. https://doi.org/10.3168/jds.S0022 $-0302(89) 79205-5$.

Oseni, S., I. Misztal, S. Tsuruta, and R. Rekaya. 2003. Seasonality of days open in US Holsteins. J. Dairy Sci. 86:3718-3725. https://doi .org/10.3168/jds.S0022-0302(03)73977-0.

Rodrigues, A. C. O., D. Z. Caraviello, and P. L. Ruegg. 2005. Management of Wisconsin dairy herds enrolled in milk quality teams. J. Dairy Sci. 88:2660-2671. https://doi.org/10.3168/jds.S0022 -0302(05)72943-X.

Salfer, I. J., P. A. Bartell, C. D. Dechow, and K. J. Harvartine. 2020. Annual rhythms of milk synthesis in dairy herds in 4 regions of the United States and their relationships to environmental indicators. J. Dairy Sci. 103:3696-3707. https://doi.org/10.3168/jds 2019-17362

Salfer, I. J., C. D. Dechow, and K. J. Harvatine. 2019. Annual rhythms of milk and milk fat and protein production in dairy cattle in the United States. J. Dairy Sci. 102:742-753. https://doi.org/10.3168/ jds.2018-15040.

Sargeant, J. M., M. M. Shoukri, S. W. Martin, K. E. Leslie, and K. D. Lissemore. 1998. Investigating potential risk factors for seasonal variation: An example using graphical and spectral analysis methods based on the production of milk components in dairy cattle. Prev. Vet. Med. 36:167-178. https://doi.org/10.1016/S0167 $-5877(98) 00089-0$. 
Schukken, Y. H., A. Weersink, K. E. Leslie, and S. W. Martin. 1993. Dynamics and regulation of bulk milk somatic cell counts. Can. J. Vet. Res. 57:131-135.

Schüller, L. K., O. Burfeind, and W. Heuwieser. 2014. Impact of heat stress on conception rate of dairy cows in the moderate climate considering different temperature-humidity index thresholds, periods relative to breeding, and heat load indices. Theriogenology 81:1050-1057. https://doi.org/10.1016/j.theriogenology.2014.01 .029 .

Schüller, L. K., O. Burfeind, and W. Heuwieser. 2016. Effect of shortand long-term heat stress on the conception risk of dairy cows under natural service and artificial insemination breeding programs. J. Dairy Sci. 99:2996-3002. https://doi.org/10.3168/jds .2015-10080.

Schüller, L. K., I. Michaelis, and W. Heuwieser. 2017. Impact of heat stress on estrus expression and follicle size in estrus under field conditions in dairy cows. Theriogenology 102:48-53. https://doi .org/10.1016/j.theriogenology.2017.07.004.

Shock, D. A., S. J. LeBlanc, K. E. Leslie, K. Hand, M. A. Godkin, J. B. Coe, and D. F. Kelton. 2015. Exploring the characteristics and dynamics of Ontario dairy herds experiencing increases in bulk milk somatic cell count during the summer. J. Dairy Sci. 98:37413753. https://doi.org/10.3168/jds.2014-8675.

Stolwijk, A. M., H. Straatman, and G. A. Zielhuis. 1999. Studying seasonality by using sine and cosine functions in regression analysis. J. Epidemiol. Community Health 53:235-238. https://doi.org/10 $.1136 /$ jech.53.4.235.

Tao, S., R. M. Orellana, X. Weng, T. N. Marins, G. E. Dahl, and J. K. Bernard. 2018. Symposium review: The influences of heat stress on bovine mammary gland function. J. Dairy Sci. 101:5642-5654. https://doi.org/10.3168/jds.2017-13727.
USDA-AMS. 2019. Milk marketing order statistics. Accessed Aug. 14, 2019. https://www.ams.usda.gov/resources/marketing-order -statistics.

USDA-APHIS, National Animal Health Monitoring System. 2014. Dairy Cattle Management Practices in the United States. Accessed Mar. 1, 2020. https://www.aphis.usda.gov/animal_health/ nahms/dairy/downloads/dairy14/Dairy14_dr_PartI_1.pdf.

USDA-ERS. 2019. Dairy data: Milk cows and production by state and region (annual). Accessed Nov. 11, 2019. https://www.ers.usda .gov/data-products/dairy-data/.

USDA-ERS. 2020. Dairy data: U.S. milk production and related data (quarterly and annual). Accessed Mar. 1, 2020. https://www.ers .usda.gov/data-products/dairy-data/.

Washburn, S. P., W. J. Silvia, C. H. Brown, B. T. McDaniel, and A. J. McAllister. 2002. Trends in reproductive performance in Southeastern Holstein and Jersey DHI herds. J. Dairy Sci. 85:244-251. https://doi.org/10.3168/jds.S0022-0302(02)74073-3.

Washington, A. A., R. L. Kilmer, and R. N. Weldon. 2002. Practices used by dairy farmers to reduce seasonal production variability. Agric. Resour. Econ. Rev. 31:127-137. https://doi.org/10.1017/ S1068280500003531.

West, J. W. 2003. Effects of heat-stress on production in dairy cattle. J. Dairy Sci. 86:2131-2144. https://doi.org/10.3168/jds.S0022 -0302(03)73803-X.

\section{ORCIDS}

Fernanda C. Ferreira (ㄴ https://orcid.org/0000-0003-2387-2269

John S. Clay ๑ https://orcid.org/0000-0001-7273-225X

Albert De Vries @ https://orcid.org/0000-0003-4511-0388 